Article

\title{
Study on Cellulose Acetate Butyrate/Plasticizer Systems by Molecular Dynamics Simulation and Experimental Characterization
}

\author{
Weizhe Wang, Lijie Li, Shaohua Jin, Yalun Wang, Guanchao Lan and Yu Chen * \\ School of Material Science and Engineering, Beijing Institute of Technology, Beijing 100081, China; \\ waxwellwang@163.com (W.W.); lilijie2003@bit.edu.cn (L.L.); jinshaohua@bit.edu.cn (S.J.); \\ 3120181161@bit.edu.cn (Y.W.); lan890805@163.com (G.L.) \\ * Correspondence: bityuchen@bit.edu.cn; Tel.: +86-10-68912370
}

Received: 10 April 2020; Accepted: 21 May 2020; Published: 2 June 2020

\begin{abstract}
Cellulose acetate butyrate $(\mathrm{CAB})$ is a widely used binder in polymer bonded explosives (PBXs). However, the mechanical properties of PBXs bonded with $\mathrm{CAB}$ are usually very poor, which makes the charge edges prone to crack. In the current study, seven plasticizers, including bis (2,2-dinitro propyl) formal/acetal (BDNPF/A or A3, which is 1:1 mixture of the two components), azide-terminated glycidyl azide (GAPA), n-butyl-N-(2-nitroxy-ethyl) nitramine (Bu-NENA), ethylene glycol bis(azidoacetate) (EGBAA), diethylene glycol bis(azidoacetate) (DEGBAA), trimethylol nitromethane tris (azidoacetate) (TMNTA) and pentaerythritol tetrakis (azidoacetate) [PETKAA], were studied for the plasticization of CAB. Molecular dynamics simulation was conducted to distinguish the compatibilities between $\mathrm{CAB}$ and plasticizers and to predict the mechanical properties of $\mathrm{CAB} /$ plasticizer systems. Considering the solubility parameters, binding energies and intermolecular radical distribution functions of these $\mathrm{CAB} /$ plasticizer systems comprehensively, we found A3, Bu-NENA, DEGBAA and GAPA are compatible with CAB. The elastic moduli of $\mathrm{CAB} /$ plasticizer systems follow the order of $\mathrm{CAB} / \mathrm{Bu}-\mathrm{NENA}>\mathrm{CAB} / \mathrm{A} 3>\mathrm{CAB} / \mathrm{DEGBAA}>\mathrm{CAB} / \mathrm{GAPA}$, and their processing property is in the order of $\mathrm{CAB} / \mathrm{Bu}-\mathrm{NENA}>\mathrm{CAB} / \mathrm{GAPA}>\mathrm{CAB} / \mathrm{A} 3>\mathrm{CAB} / \mathrm{DEGBAA}$. Afterwards, all the systems were characterized by FT-IR, differential scanning calorimetry (DSC), differential thermogravimetric analysis (DTA) and tensile tests. The results suggest A3, GAPA and Bu-NENA are compatible with CAB. The tensile strengths and Young's moduli of these systems are in the order of $\mathrm{CAB} / \mathrm{A} 3>\mathrm{CAB} / \mathrm{Bu}-\mathrm{NENA}>\mathrm{CAB} / \mathrm{GAPA}$, while the strain at break of $\mathrm{CAB} / \mathrm{Bu}-\mathrm{NENA}$ is best, which are consistent with simulation results. Based on these results, it can be concluded that $A 3$, Bu-NENA and GAPA are the most suitable plasticizers for CAB binder in improving mechanical and processing properties. Our work has provided a crucial guidance for the formulation design of PBXs with $\mathrm{CAB}$ binder.
\end{abstract}

Keywords: cellulose acetate butyrate; plasticizer; molecular dynamics simulation; thermal analysis; compatibility

\section{Introduction}

Cellulose acetate butyrate $(\mathrm{CAB})$, with the molecular formula of $\left[\mathrm{C}_{6} \mathrm{H}_{7} \mathrm{O}_{2}-\left(\mathrm{OCOCH}_{3}\right) \mathrm{x}-\left(\mathrm{OCOC}_{3}\right.\right.$ $\left.\left.\mathrm{H}_{7}\right)_{\mathrm{Y}^{-}}(\mathrm{OH})_{3-\mathrm{X}-\mathrm{Y}}\right]_{n}$, is the most commonly used binder in polymer bonded explosives (PBXs). In the structure of cellulose ester, hydroxyl groups are co-esterified with acetic acid and butyric acid [1]. Therefore, $\mathrm{CAB}$ contains about $12-15 \%$ (wt \%) of acetyl groups and $26-39 \%$ (wt \%) of butyryl groups, which endows it with excellent physical and chemical properties including outstanding moisture resistance, UV resistance, temperature resistance, flexibility, transparency, etc. Therefore, many 
researchers have utilized this excellent cellulose derivative in the field of energetic materials. $\mathrm{Li}$ prepared the CL-20 based pressed PBXs with CAB as binder for its excellent compatibility and mechanical properties [2]. Lan ameliorated the HNIW based PBXs with excellent temperature adaptability using $\mathrm{CAB}$ and fluorine rubber $\mathrm{F} 2311$ as binders [3].

However, the CAB-bonded explosives exhibit some defects and encounter problems in their practical applications. The softening temperature $\left(T_{S}\right)$ and glass transition temperature $\left(T_{g}\right)$ of $C A B$ are relatively high. Therefore, its molecular chain cannot stretch sufficiently and its adhesion is weak in solvents. The PBXs with $\mathrm{CAB}$ as binder usually exhibit poor mechanical properties at low temperatures, unsatisfactory insensitivity, and deterioration of cracks [4].

To ameliorate these situations, plasticizers have been added to the CAB binder system to lower its $\mathrm{T}_{\mathrm{S}}$ and $\mathrm{T}_{\mathrm{g}}$, increase its plasticity, improve the mechanical properties and insensitivity, and prevent the deterioration of cracks on PBXs [5]. However, the effects of different plasticizers on properties of PBXs with CAB binder remain unclear. Therefore, it is essential to select optimal plasticizers for $\mathrm{CAB}$ binder system of PBXs. Experimental tests are time-consuming and inconvenient for repeated comparisons, accompanied by certain risks. In addition, it cannot be used for the in-depth analysis from the microscopic perspective.

Molecular dynamics (MD) simulation has been widely used to predict the compatibility and mechanical properties of blends [6-9]. Compared with the macroscopic experiments, MD simulations in microscopic scales not only can reveal the effects of plasticizer at the atomic and molecular levels, but also is low-cost and time efficient. Therefore, it can be used to study the effects of different plasticizers on CAB binder quickly and efficiently [10]. In the present work, the compatibilities between $C A B$ and different plasticizers were evaluated by MD simulation. The mechanical properties of the plasticized $\mathrm{CAB}$ with selected plasticizers were then simulated. Three representative $\mathrm{CAB} /$ plasticizer systems were prepared, and their compatibilities, chemical stability and mechanical properties were characterized experimentally, aiming to establish a study method combining MD simulation and experimental characterization for optimizing $\mathrm{CAB} /$ plasticizer systems. Our work has provided a guidance and reference for the subsequent modification of $\mathrm{CAB}$ binder and the formulation design of $\mathrm{PBX}$ using CAB binder.

\section{MD Simulation}

Based on their molecular structures (Figure 1), the molecular models of $\mathrm{CAB}$ and plasticizers including bis (2,2-dinitro propyl) formal/acetal (BDNPF/A or $\mathrm{A} 3$, which is 1:1 mixture of the two components), azide-terminated glycidyl azide (GAPA), n-butyl-N-(2-nitroxy-ethyl) nitramine (Bu-NENA), ethylene glycol bis(azidoacetate) (EGBAA), diethylene glycol bis(azidoacetate) (DEGBAA), trimethylol nitromethane tris (azidoacetate) (TMNTA) and pentaerythritol tetrakis(azidoacetate) (PETKAA) were constructed using the Visualizer module in Material Studio (MS) version 6.0. The butyryl group and acetyl group contents in $\mathrm{CAB}$ are approximately set to $37 \mathrm{wt} \%$ and $13 \mathrm{wt} \%$, respectively. Anneal and geometric optimizations were then conducted to establish the final molecular models. 

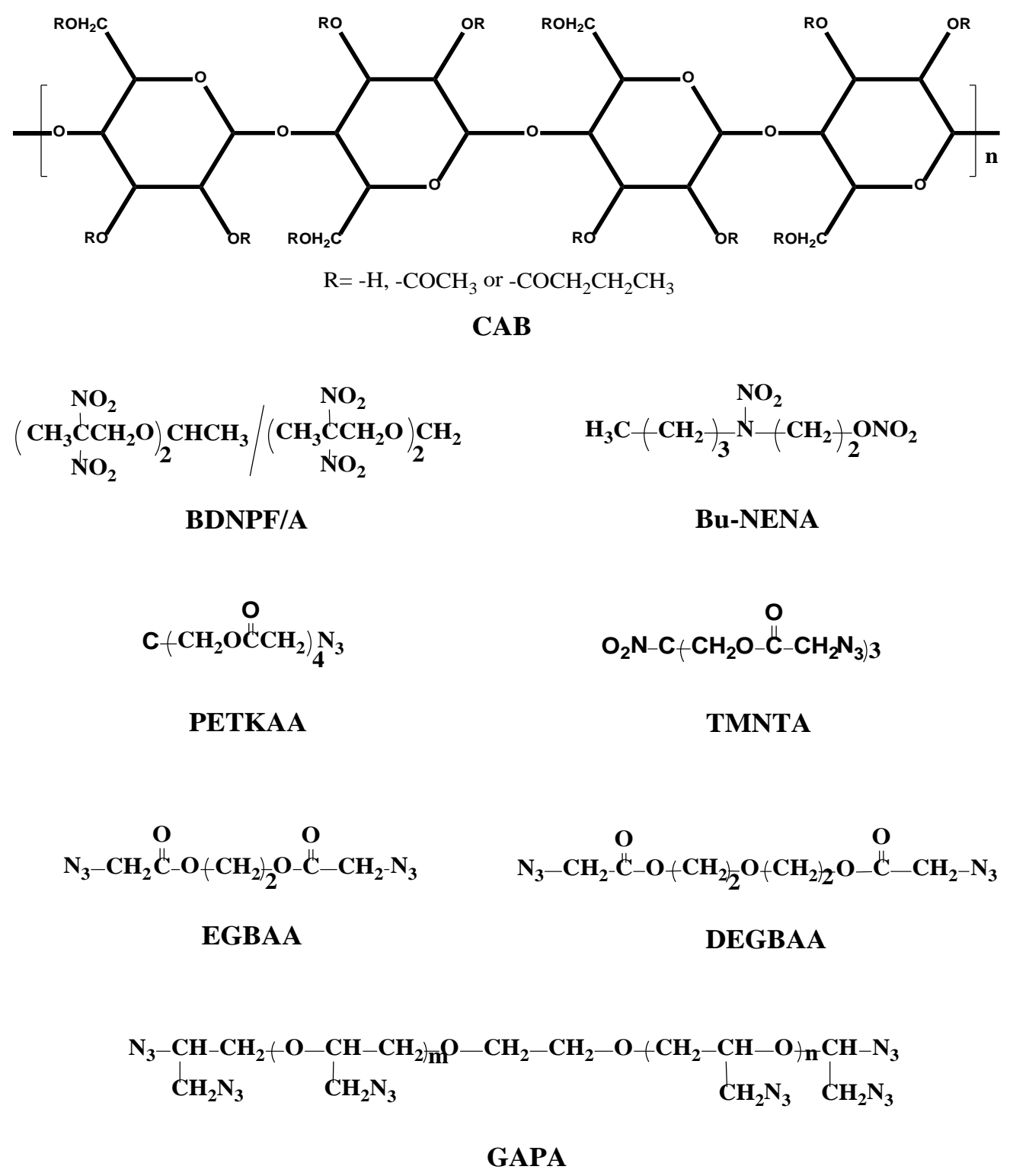

(a)

Figure 1. Cont. 

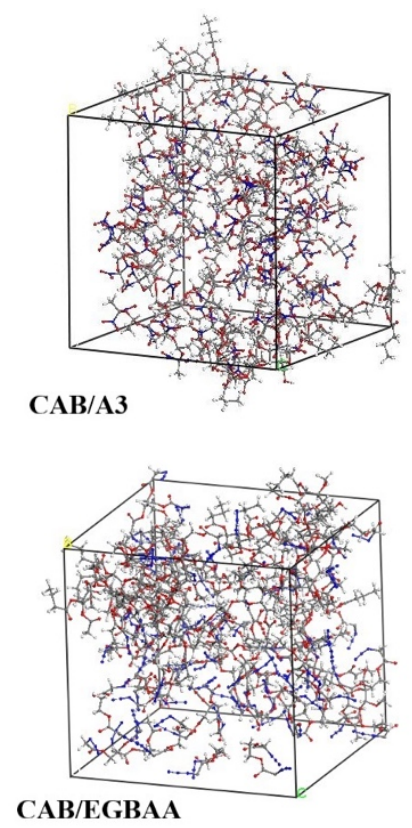
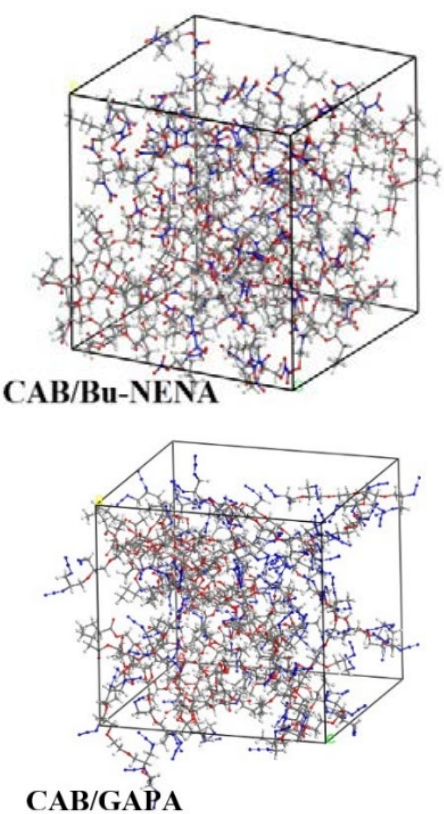

CAB/GAPA

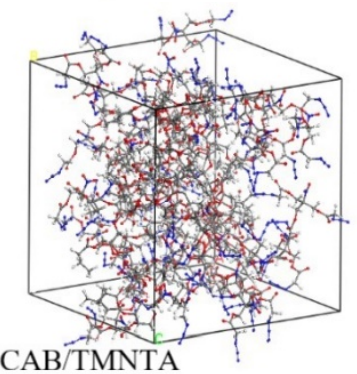

\section{(b)}
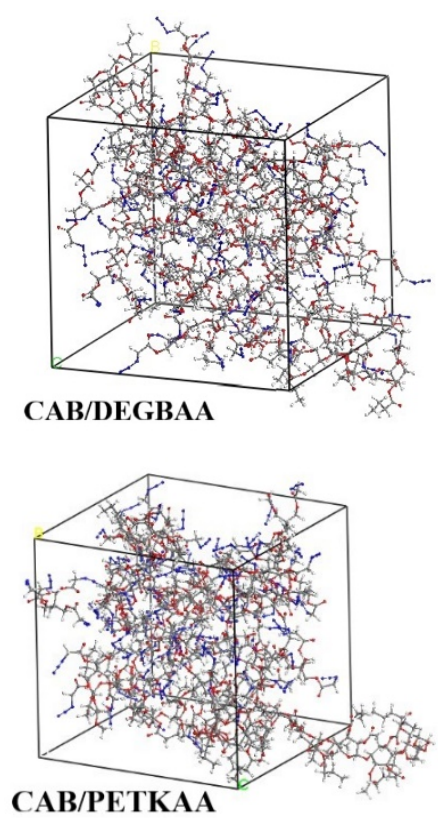

CAB/PETKAA

Figure 1. Molecular structures (a) and amorphous models $(\mathbf{b})$ of $\mathrm{CAB} /$ plasticizer systems. $\mathrm{CAB}=$ cellulose acetate butyrate.

\subsection{Construction of Models}

To evaluate the compatibility between $\mathrm{CAB}$ and plasticizers and predict the mechanical properties of the plasticized CAB, MD simulation was conducted in the Material Studio with use of COMPASS force field [11].

The next simulation section is the annealing of various molecular models, which aims to relax their configurations, lower the potential energy and eliminate the internal stress of polymer chains. The initial temperature and mid-cycle temperature were set to $298 \mathrm{~K}$ and $500 \mathrm{~K}$, respectively. The temperature range covers different glass transition temperatures $\left(T_{g}\right)$ of $C A B$ and plasticizers $(C A B$ : 403.2K, BDNPF/A: 208.6K, Bu-NENA: 189.7K, EGBAA: 203.7K, DEGBAA: 209.9K, GAPA: 194.4K, PETKAA: 237.8K, TMNTA: 239.1K) [12-18]. The heating ramps per cycle was 25, which was a proper step number. Too rapid cooling often traps the system in a high energy-low density state that cannot represent the glassy state. In the contrast, slow annealing from rubbery state with high $\mathrm{T}_{\mathrm{g}}$ can generate more accurate results. After 500 cycles of annealing, the annealed molecular models were obtained for further simulation.

The amorphous models of $\mathrm{CAB} /$ plasticizer systems were then established using the Amorphous Cell module as shown in Figure 1. For the construction of these amorphous models, the quality was set to fine, the maximum number of steps was set to 50,000, and the density of the mixed system was calculated based on the mass ratio of $\mathrm{CAB} /$ plasticizer. Ewald was set as the electrostatic force, van der Waals was set as the atom based, and cutoff radius was set to $12.50 \AA$ for the simulation. The mass ratio of $\mathrm{CAB}$ /plasticizer was set to 2:3, which is a commonly used ratio in PBXs, and the amounts of $\mathrm{CAB}$ 
molecules ( 3 chains, 734 atoms) in all amorphous models were the same. The plasticizer contents were approximately in the range of 30-60 molecules (1200-1800 atoms) in different systems, depending on the plasticizer.

\subsection{Calculations}

The geometric structures of $\mathrm{CAB} /$ plasticizer amorphous models were optimized by "Geometry Optimization" option in the Forcite module. The MD simulation of 250 ps was performed in NVT ensemble at the temperature of $298 \mathrm{~K}$ to achieve the optimal amorphous models [19]. COMPASS force field was applied with Andersen thermostat for the simulation. Figure 2 shows the dynamics temperature-time curve and energy-time curves obtained by MD simulation. The simulation is considered to reach the equilibrium state if the fluctuations of dynamic temperature and dynamic energy are less than 5\% [20]. The dynamic energy may seem almost constant during the simulation, but it changes slightly with time, which is so-called "aging".

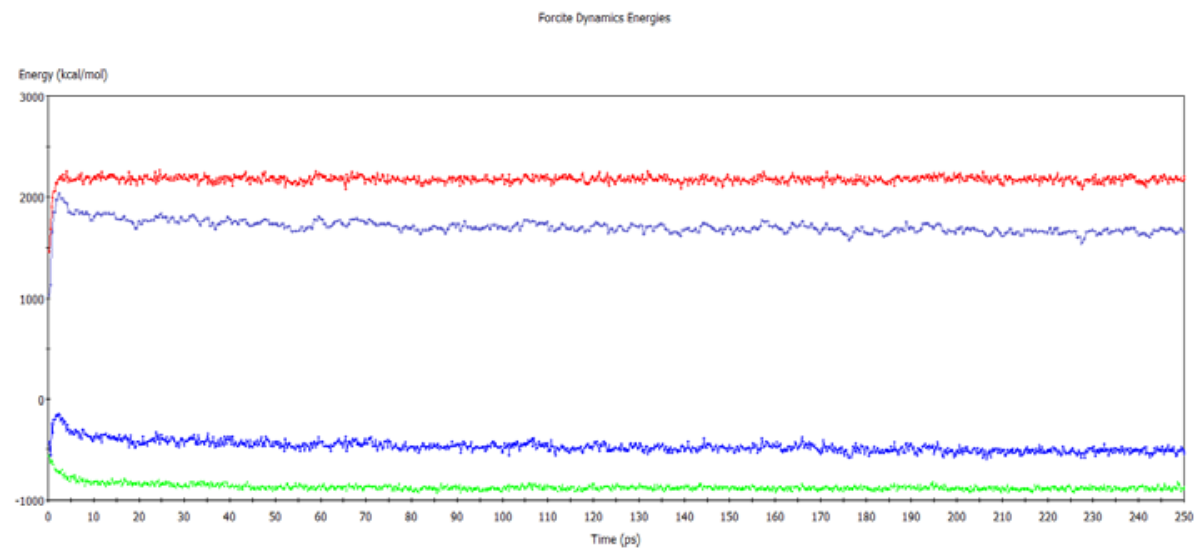

(a)

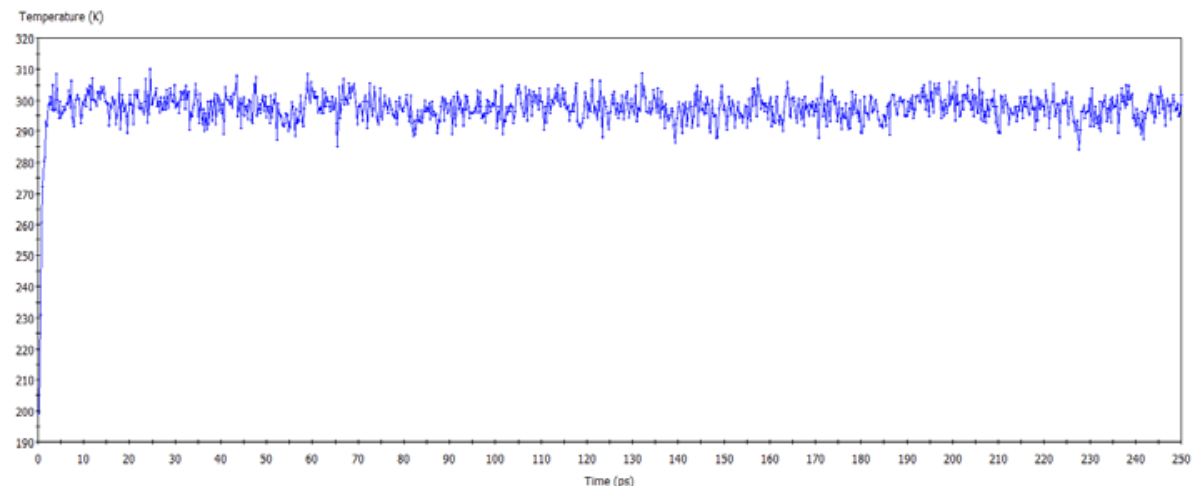

(b)

Figure 2. Dynamic energy-time (a) and temperature-time (b) curves of the molecular dynamics (MD) simulation. The red, light blue, dark blue and green curves in (a) represent kinetic energy, total energy, potential energy and non-bonded energy, respectively.

After dynamics simulation reaching the equilibrium state, the calculated dynamic trajectory files were analyzed by the "Cohesive Energy Density" option of the Forcite module to obtain the cohesive energy density and solubility parameters of $C A B$ and plasticizers.

The binding energies of $\mathrm{CAB}$, plasticizers and their mixed systems were produced by the analysis with "Total Kinetic Energy" option in Forcite module. Five frames of each model with lowest energy were selected and their binding energy parameters were obtained with "Energy" option in Forcite, which were then averaged. 
Radial distribution functions (RDF) were obtained by the analysis with "Radial distribution function" option of Forcite module. The dynamic trajectory files of the CAB molecules and plasticizers were classified to different sets and analyzed with "Radial distribution function" option to give RDFs.

The mechanical properties of the systems were simulated in a more complex manner. The amorphous models of $\mathrm{CAB} /$ plasticizers were firstly subjected to the 250 ps dynamics simulation with NPT ensemble under 1GPa. The last frame model of previous dynamic trajectory files was extracted to subject to another 250 ps dynamics simulation with the NPT ensemble under 1atm. The last frame model was then extracted to undergo the 250 ps dynamics simulation with NVT ensemble and the final dynamic trajectory files were calculated by "Mechanical Properties" option in Forcite module. The simulation tests were performed by the "Constant strain" method. The number of steps for each strain was set to 4 and the maximum strain was $3 \times 10^{-3}$. The strain rate was used as the automatic systematical setting.

\section{Experiments and Characterization}

\subsection{Materials}

Three representative plasticizers, A3, GAPA and Bu-NENA, were selected for experimental characterization. Analytical grade $\mathrm{CAB}$ containing $37 \mathrm{wt} \%$ butyryl group and $13 \mathrm{wt} \%$ acetyl group was purchased from Eastman Chemical Company (USA). A3 and Bu-NENA (purity $>99.9 \%$ ) were provided by Liming Chemical Research Institute (Henan, China). GAPA (purity $>99.12 \%, \rho=1.21 \mathrm{~g} / \mathrm{cm}^{3}$, water content $<0.016 \%$, hydroxyl value $\approx 1.5 \mathrm{mg} \mathrm{KOH} / \mathrm{g}$, molecular weight $\mathrm{Mn} \approx 800 \mathrm{~g} / \mathrm{mol}$ ) was synthesized in-house.

\subsection{Preparation of $C A B /$ Plasticizer Mixed Systems}

$\mathrm{CAB}$ and plasticizer were mixed at the mass ratio of 2:3. For a typical procedure, $2.00 \mathrm{~g} \mathrm{CAB}$ was dissolved in $20 \mathrm{~mL}$ ethyl acetate in a $50 \mathrm{~mL}$ flask by magnetic stirring, and $3.00 \mathrm{~g}$ plasticizer was then added into the flask and mixed well with $C A B$ solution. Ethyl acetate was then removed by evaporation under reduced pressure with a rotary evaporator to afford the $\mathrm{CAB} /$ plasticizer mixture.

\subsection{Characterizations}

The structure of $\mathrm{CAB} /$ plasticizer was characterized using a Fourier transform infrared spectroscopy (FT-IR) analyzer (NEXUS-470, Nicolet, WI, USA) by the KBr pellet method.

The compatibilities between $\mathrm{CAB}$ and plasticizers were respectively evaluated by differential scanning calorimetry (DSC) using a DSC131 Evo instrument (Setaram, France) and differential thermogravimetric analysis (DTA) using a DTA-60 thermal analyzer (Shimadzu, Japan) under $50 \mathrm{~mL} / \mathrm{min}$ nitrogen flow atmosphere at the heating rate of $10 \mathrm{~K} / \mathrm{min}$.

The tensile strengths of the mixed systems were measured using a universal material testing machine (6022, Instron, Norwood, MA, USA) at the loading rate of $100 \mathrm{~mm} / \mathrm{min}$ until broken. Ten test specimens were prepared and characterized, whose size were $20 \mathrm{~mm}$ long and $5 \mathrm{~mm}$ wide.

\section{Results and Discussion}

\subsection{Simulation}

\subsubsection{Solubility Parameter}

According to the polymer solution theory, the mixture of polymer and plasticizer can be considered as polymer solution system [21]. The necessary thermodynamic condition for a spontaneous dissolution at constant temperature under constant pressure is:

$$
\Delta G_{M}=\Delta H_{M}-T \Delta S_{M}<0
$$


where $\Delta G$ is the free energy of mixing, $\Delta S$ is the entropy of mixing, $\Delta H$ is the heat of mixing, and $T$ is the temperature of dissolution. As a polymer is mixed with a plasticizer, the polymer itself is in a chaotic state. Therefore, the magnitude of $\Delta G$ mainly depends on $\Delta H$ [22]. Hildebrand introduced the concept of solubility parameter $(\delta)$ [23], which was defined as the square root of the cohesive energy density (CED) (Equation (2)).

$$
\delta=(\Delta E / V)^{1 / 2}=[(\Delta H-R T) / V]^{1 / 2}
$$

The heat of mixing $\Delta H_{M}$ of the polymer dissolution can be expressed using the Hildebrand formula of small molecules:

$$
\Delta H_{M}=V_{M} \Phi_{1} \Phi_{2}\left[\left(\Delta E_{1} / V_{1}\right)^{1 / 2}-\left(\Delta E_{2} / V_{2}\right)^{1 / 2}\right]^{2}
$$

where $\Phi_{1}$ and $\Phi_{2}$ are the volume fractions of the two components, respectively, and $V$ is the molar volume of the mixture. If the square root of CED is replaced with $\delta$, Equation (3) can be re-written as:

$$
\Delta H_{M}=V_{M} \Phi_{1} \Phi_{2}\left(\delta_{1}-\delta_{2}\right)^{2}
$$

Therefore, the value of $\Delta H_{M}$ is determined by $\delta_{1}$ and $\delta_{2}$. The closer $\delta_{1}$ and $\delta_{2}$ are, the smaller $\Delta H_{M}$ is and the better the compatibility of the two components will be. For an energetic material, its polymer and plasticizer are generally considered compatible if $|\Delta \delta|<3.68 \sim 4.06\left(\mathrm{~J}^{1 / 2} \cdot \mathrm{cm}^{-3 / 2}\right)$ [24].

Table 1 lists the solubility parameters $\left(\delta_{M D}\right)$ of $C A B$ and each plasticizer, and the respective differences between the solubility parameters of $C A B$ and those of different plasticizers $\left(\left|\Delta \delta_{M D}\right|\right)$ obtained by the MD simulation. The difference between the simulation $\delta$ of $C A B$ (17.29) and reported $\delta$ (18.87) is very small $[25,26]$, indicating that although MD simulation produces statistical uncertainties from the ideal simulation conditions and imperfection algorithm, the simulation results are mostly consistent with reality.

Table 1. Solubility parameters $\left(\delta_{M D}\right)$ of $\mathrm{CAB}$ and each plasticizer and the respective differences $\left(\left|\Delta \delta_{M D}\right|\right)$ between the solubility parameters of $\mathrm{CAB}$ and different plasticizers.

\begin{tabular}{ccc}
\hline Component & $\delta_{M D} /\left(\mathbf{J}^{\left.\mathbf{1 / 2} \cdot \mathbf{c m}^{-3 / 2}\right)}\right.$ & $\left|\Delta \delta_{M D}\right| /\left(\mathbf{J}^{\mathbf{1 / 2}} \cdot \mathbf{c m}^{-3 / 2}\right)$ \\
\hline CAB & 17.29 & 0 \\
A3 & 20.01 & 2.72 \\
GAPA & 20.56 & 3.27 \\
EGBAA & 23.59 & 6.20 \\
DEGBAA & 18.72 & 1.43 \\
TMNTA & 24.55 & 7.26 \\
Bu-NENA & 20.84 & 3.55 \\
PETKAA & 23.30 & 6.01 \\
\hline
\end{tabular}

The $\left|\Delta \delta_{M D}\right|$ values between CAB and A3, GAPA, DEGBAA and Bu-NENA plasticizer are less than 3.55 , suggesting that these plasticizers are compatible with $C A B$. However, the values of $\left|\Delta \delta_{M D}\right|$ between CAB and EGBAA, TMNTA and PETKAA are greater than 6.00, indicating that these plasticizers are unsuitable for the plasticization of $\mathrm{CAB}$.

\subsubsection{Binding Energy}

The good compatibility between a polymer and a different compound implies strong intermolecular interaction(s) between them. The strength of such interaction can be quantitatively described with binding energy $\left(E_{\text {bind }}{ }^{\prime}\right)$. The average interaction energy between $\mathrm{CAB}$ and a plasticizer $\left(E_{\text {inter }}\right)$ can be defined as:

$$
E_{\text {inter }}=E_{\text {total }}-\left(E_{C A B}+E_{\text {plasticizer }}\right)
$$


where $E_{\text {total }}$ is the total energy of the mixed system, and $E_{C A B}$ and $E_{\text {plasticizer }}$ are the average energies of $\mathrm{CAB}$ and plasticizer, respectively. The binding energy $E_{\text {bind }}$ is the negative value of the average interaction energy $E_{\text {inter }}$, e.g.:

$$
E_{\text {bind }}=-E_{\text {inter }}
$$

Because the average molecular weights of the mixed systems are different, the binding energy is converted into per unit mass $E_{\text {bind }}$ ' for comparison purpose as shown in Equation (7):

$$
E_{\text {bind }}{ }^{\prime}=E_{\text {bind }} / M_{n}
$$

where $M_{n}$ is the average molecular weight calculated based on the mass ratio of $C A B /$ plasticizer.

Table 2 lists the $E_{\text {bind }}$ and $E_{\text {bind }}$ ' of each $\mathrm{CAB} /$ plasticizer system. No chemical bonds contribute to the binding energy. The binding energies are numerically equal to the corresponding non-bonding energies and follow the order of $\mathrm{CAB} / \mathrm{Bu}-\mathrm{NENA} \approx \mathrm{CAB} / \mathrm{EGBAA}>\mathrm{CAB} / \mathrm{DEGBAA}>\mathrm{CAB} / \mathrm{TMNTA}>$ $\mathrm{CAB} / \mathrm{PETKAA}>\mathrm{CAB} / \mathrm{GAPA}>\mathrm{CAB} / \mathrm{A} 3$. It is known that the system with greater $E_{\text {bind }}$ ' has better compatibility [27]. Therefore, $\mathrm{CAB} / \mathrm{A} 3$ is the least compatible system and all other $\mathrm{CAB} /$ plasticizer systems are more compatible. The discrepancy with Solubility Parameter simulation results is mainly generated from the ideal simulation conditions and imperfection algorithms. Although the solubility parameter is the most reliable criteria for compatibility, binding energy can also provide supplementary information.

Table 2. The binding energies $\left(E_{\text {bind }}\right)$ and per unit mass binding energies $\left(E_{\text {bind }}{ }^{\prime}\right)$ between $\mathrm{CAB}$ and

\begin{tabular}{|c|c|c|c|c|c|}
\hline System & $E_{\text {valence }} / \mathrm{kcal} \cdot \mathrm{mol}^{-1}$ & $E_{v d w} /{\mathrm{kcal} \cdot \mathrm{mol}^{-1}}^{-1}$ & $E_{\text {elect }} / \mathbf{k c a l} \cdot \mathrm{mol}^{-1}$ & $E_{\text {bind }} /{\mathrm{kcal} \cdot \mathrm{mol}^{-1}}^{-1}$ & $E_{\text {bind }}{ }^{\prime} / \mathrm{kcal} \cdot \mathrm{g}^{-1}$ \\
\hline $\mathrm{CAB} / \mathrm{A} 3$ & 0 & -448.44 & -149.96 & 598.40 & 0.71 \\
\hline CAB/GAPA & 0 & -565.11 & -116.36 & 681.47 & 0.91 \\
\hline CAB/PETKAA & 0 & -596.22 & -157.32 & 753.55 & 1.08 \\
\hline CAB/EGBAA & 0 & -578.03 & -144.21 & 722.25 & 2.03 \\
\hline CAB/Bu-NENA & 0 & -550.03 & -115.85 & 665.88 & 2.03 \\
\hline CAB/TMNTA & 0 & -600.74 & -153.22 & 753.96 & 1.25 \\
\hline CAB/DEGBAA & 0 & -562.56 & -138.11 & 700.67 & 1.65 \\
\hline
\end{tabular}
different plasticizers.

\subsubsection{Radial Distribution Function (RDF)}

In statistical mechanics, the RDF of a system of different particles (atoms, ions, molecules, etc.) is applicable to the structural investigations of both solid and liquid packing (local structure) for studying specific interactions, such as hydrogen bonding. It measures the probability of finding a target particle at the distance of $r$ around the given reference particle [28]. In other words, it describes how the density varies with distance from a reference particle [29]. In a blend of various molecules, two different components tend to be compatible with each other if the RDF curve of mixed system is higher than each of their own [30]. Figure 3 shows the radial distribution functions (RDFs) of different $\mathrm{CAB} /$ plasticizer systems and those of their individual components. 

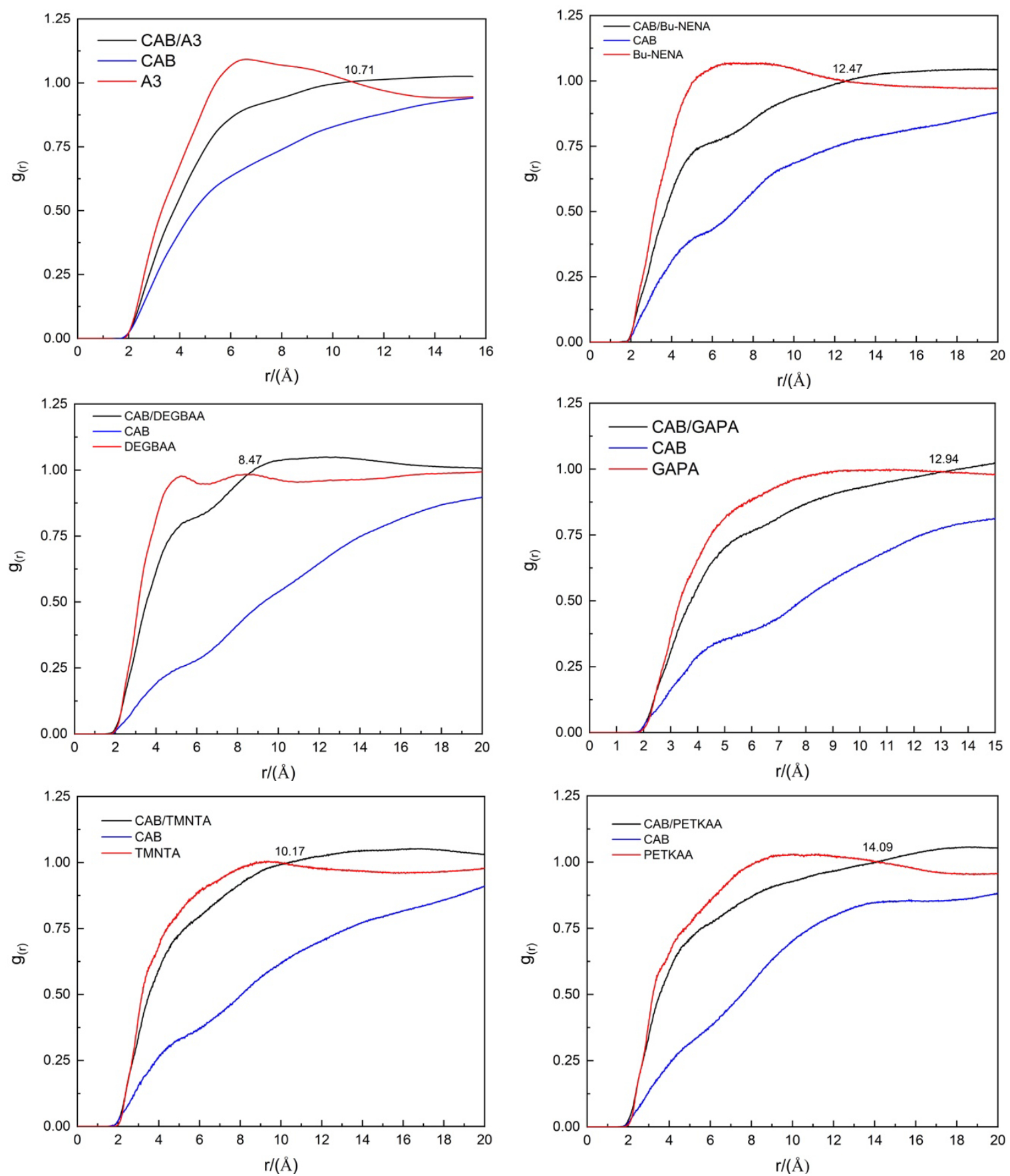

Figure 3. Radial distribution functions (RDF) curves of different $\mathrm{CAB} /$ plasticizer systems.

The RDFs of $\mathrm{CAB}$ and all plasticizers reach the peak values at the distances slightly shorter than 5.00-6.00 $\AA$. It is well known that the distance ranges of hydrogen bond and van der Waals force are 0-3.10 $\AA$ and 3.10-5.00 $\AA$, respectively [31-34]. Therefore, van der Waals force is the major intermolecular forces of $\mathrm{CAB}-\mathrm{CAB}$ and plasticizer-plasticizer pairs. The RDF of $\mathrm{CAB} /$ plasticizer is lower than that of plasticizer, but higher than $C A B$ itself in the range of 0-6.00 $\AA$ for all systems, suggesting that the compatibility between $C A B$ and plasticizers seems not so good.

The RDF curves of $\mathrm{CAB} / \mathrm{Bu}-\mathrm{NENA}, \mathrm{CAB} / \mathrm{GAPA}$ and $\mathrm{CAB} / \mathrm{PETKAA}$ are higher than themselves at the distances longer than $12.47 \AA, 12.94 \AA$ and $14.09 \AA$, which are far beyond the range of intermolecular forces, indicating these plasticizers are not compatible with $\mathrm{CAB}$. The nitro and azide groups in their 
structure may be the main reason of the weak physical interactions between these groups and cellulose chains of $\mathrm{CAB}$.

The RDF curves of $C A B / A 3, C A B / D E G B A A$, and $C A B / T M N T A$ are higher than those of the corresponding plasticizers at distances longer than $10.71 \AA, 8.41 \AA$ and $10.17 \AA$, indicating that these plasticizers are compatible with $\mathrm{CAB}$. These results suggest that compatibilities of $\mathrm{CAB} / \mathrm{A} 3, \mathrm{CAB} / \mathrm{DEGBAA}$, and CAB/TMNTA are better than those of CAB/GAPA, CAB/Bu-NENA and CAB/PETKAA.

Considering three compatibility criteria including solubility parameter, binding energy and radial distribution function (RDF) comprehensively, it can be concluded that GAPA, Bu-NENA, A3 and DEGBAA are compatible with CAB, and PETKAA, TMNTA and EGBAA are incompatible with CAB.

\subsubsection{Simulation of Mechanical Properties}

The mechanical properties of an energetic material greatly affect the safety and storage performance of its explosive products, which thus are of significant importance [35]. Bulk modulus $(K)$, shear modulus $(G)$, Poisson's ratio $(\mu)$, Young's modulus $(E)$, etc. are usually used to describe the mechanical properties of energetic materials.

The volume of a material decreases under uniform pressure $P$. Therefore, bulk modulus is defined as:

$$
K=\frac{P}{-\Delta V / V}=-\frac{P V}{\Delta V}
$$

where $V$ is the volume of material and $\Delta V$ is the volume change under pressure $P$. Bulk modulus is a measure of compressibility and breaking strength of a material. The larger the bulk modulus, the higher the breaking strength [36].

Shear modulus $(G)$ is the ratio of shear stress $(\sigma)$ to shear strain $(\gamma)$ :

$$
G=\frac{\sigma}{\gamma}=\frac{P / A}{\operatorname{tg} \theta}
$$

It is a measure of the stiffness of a material. The greater the value of shear modulus, the higher the material hardness and the smaller the deformation.

The ratio of bulk modulus to shear modulus $(K / G)$ reflects the extent of plastic change (elongation in tension) of the material. The greater the value of $K / G$ is, the better the ductility of the material is [37].

Young's modulus $(E)$ is defined as the ratio of tensile stress $(\sigma)$ to tensile strain $\left(\varepsilon_{1}\right)$ :

$$
E=\frac{\sigma}{\varepsilon_{1}}
$$

It can be used to evaluate the capability of a material to resist deformation and volume change caused by external stresses.

Poisson's ratio $(\mu)$ is defined as the ratio of transverse shrinkage deformation $\left(\varepsilon_{2}\right)$ to longitudinal stretch deformation $\left(\varepsilon_{1}\right)$ :

$$
\mu=-\frac{\varepsilon_{2}}{\varepsilon_{1}}
$$

It is an elastic constant reflecting the transverse deformation of a material. In general, the $\mu$ less than 0.5 under tensile stress results in volume increases. The materials with the Poisson's ratios in the range between 0.2 and 0.4 are generally considered to have good plasticity [38-41].

The moduli of a typical isotropic material satisfy the following relationship [42]:

$$
E=2 G(1+\mu)=3 K(1-2 \mu)
$$

Table 3 lists the bulk moduli $(K)$, shear moduli $(G)$ and other calculated mechanical parameters of the $\mathrm{CAB} /$ plasticizer systems obtained by MD simulation. $\mathrm{CAB} / \mathrm{Bu}-\mathrm{NENA}$ exhibits the largest bulk modulus $(K)$, indicates that its breaking strength is the highest. The shear moduli $(G)$ of the 
$\mathrm{CAB} /$ plasticizer systems are similar, within the range of $0.8-0.9 \mathrm{GPa}$. The Poisson's ratio $(\mu)$ and the $K / G$ value of $\mathrm{CAB} / \mathrm{Bu}-\mathrm{NENA}$ are also the greatest, indicating its ductility and formation property are the best. The Young's modulus $(E)$ of the $\mathrm{CAB} / \mathrm{Bu}-\mathrm{NENA}$ system is greatest, suggesting its resistance to deformation is the highest. The discrepancy between simulation results and actual mechanical parameters is mainly generated from the ideal simulation conditions and imperfection algorithms.

Table 3. The mechanical parameters of $\mathrm{CAB} /$ plasticizers.

\begin{tabular}{cccccc}
\hline System & K/GPa & G/GPa & K/G & $\mu$ & E/GPa \\
\hline CAB/A3 & 2.32 & 0.86 & 2.70 & 0.34 & 2.29 \\
CAB/GAPA & 2.50 & 0.78 & 3.20 & 0.36 & 2.13 \\
CAB/DEGBAA & 1.54 & 0.91 & 1.70 & 0.25 & 2.27 \\
CAB/Bu-NENA & 5.23 & 0.89 & 5.87 & 0.42 & 2.53 \\
CAB/TMNTA & 2.53 & 1.02 & 2.49 & 0.32 & 2.69 \\
CAB/PETKAA & 2.26 & 1.34 & 1.68 & 0.25 & 3.36 \\
CAB/EGBAA & 2.24 & 0.83 & 2.69 & 0.33 & 2.22 \\
\hline
\end{tabular}

Based on the simulated mechanical properties obtained above, it can be concluded that the mechanical properties of $C A B / B u-N E N A$ are the best, followed by those of $C A B / A 3$ and $C A B / G A P A$. The mechanical properties of CAB/DEGBAA are poorest.

\subsection{Experimental Characterization}

Based on the simulation results, $\mathrm{CAB} / \mathrm{A} 3, \mathrm{CAB} / \mathrm{GAPA}$ and $\mathrm{CAB} / \mathrm{Bu}-\mathrm{NENA}$ mixed systems were prepared, and their compatibilities and mechanical properties were characterized by FT-IR, DSC, DTA and tensile strength tests for comparison purpose. The feasibility to optimize the plasticity of binder and predict the mechanical properties of the plasticized binder by combining theoretical simulation and experimental characterization was further demonstrated.

\subsubsection{Chemical Stability}

The chemical stability of an energetic material can be determined by FT-IR. If the characteristic peaks of mixture are the same as those of raw materials, it can be considered no chemical change occurs during the mixing [43]. Figure 4 shows the FT-IR spectra of $C A B$, plasticizers and their mixed products.

The $\mathrm{CAB} / \mathrm{GAPA}$ system is analyzed as an example. $\mathrm{CAB}$ exhibits a broad and strong absorption peak at $3445.86 \mathrm{~cm}^{-1}$ due to the stretching vibration of $-\mathrm{OH}$. The doublet peak at $2964.33 \mathrm{~cm}^{-1}$ and $2877.88 \mathrm{~cm}^{-1}$ are attributed to the antisymmetric and symmetric stretching vibrations of methylene group. The strong absorption peak at $1742.35 \mathrm{~cm}^{-1}$ can be assigned to the stretching vibration of $-\mathrm{C}=\mathrm{O}$. The peaks at $1165.11 \mathrm{~cm}^{-1}$ and $1065.15 \mathrm{~cm}^{-1}$ are ascribed to the stretching vibration of the unique -COCOC-polyether structure in CAB.

GAPA shows a doublet peak at $2929.89 \mathrm{~cm}^{-1}$ and $2877.42 \mathrm{~cm}^{-1}$ that can be assigned to the antisymmetric and symmetric stretching vibration of methylene. The strong peak at $2100.68 \mathrm{~cm}^{-1}$ and the peak at $1281.22 \mathrm{~cm}^{-1}$ are the characteristic absorption peaks of GAPA caused by the stretching vibration and bending vibration of $-\mathrm{N}_{3}$, respectively. The peak at $1128.16 \mathrm{~cm}^{-1}$ can be assigned to the antisymmetric stretching vibration of ether bond.

The stretching vibration of $-\mathrm{OH}$ remains at $3462.72 \mathrm{~cm}^{-1}$ in the $\mathrm{CAB} / \mathrm{GAPA}$ mixture. The peaks of the mixture at $2934.93 \mathrm{~cm}^{-1}$ and $2879.95 \mathrm{~cm}^{-1}$ are due to the superposition of the antisymmetric and symmetric stretching vibration absorption peaks of the methylene groups in CAB and GAPA. The stretching vibration peak of $-\mathrm{N}_{3}$ of GAPA shifts to $2097.35 \mathrm{~cm}^{-1}$. The stretching vibration peak of $-\mathrm{C}=\mathrm{O}$ of $\mathrm{CAB}$ is found at $1730.42 \mathrm{~cm}^{-1}$. The peak at $1275.13 \mathrm{~cm}^{-1}$ is attributed to the bending vibration of the $-\mathrm{N}_{3}$ of GAPA. The stretching vibration of -COCOC- polyether structure of CAB results in the absorption peak at $1202.30 \mathrm{~cm}^{-1}$. Based on these results, it can be concluded that no chemical reaction occurs during the mixing, and thus the chemical properties of the mixture systems are relatively stable. 
Similar results are obtained for the $\mathrm{CAB} / \mathrm{Bu}-\mathrm{NENA}$ and $\mathrm{CAB} / \mathrm{A} 3$ systems. Therefore, mixing $\mathrm{CAB}$ with plasticizers does not change the chemical properties of the individual components, and the $\mathrm{CAB} /$ plasticizer systems are chemically stable.
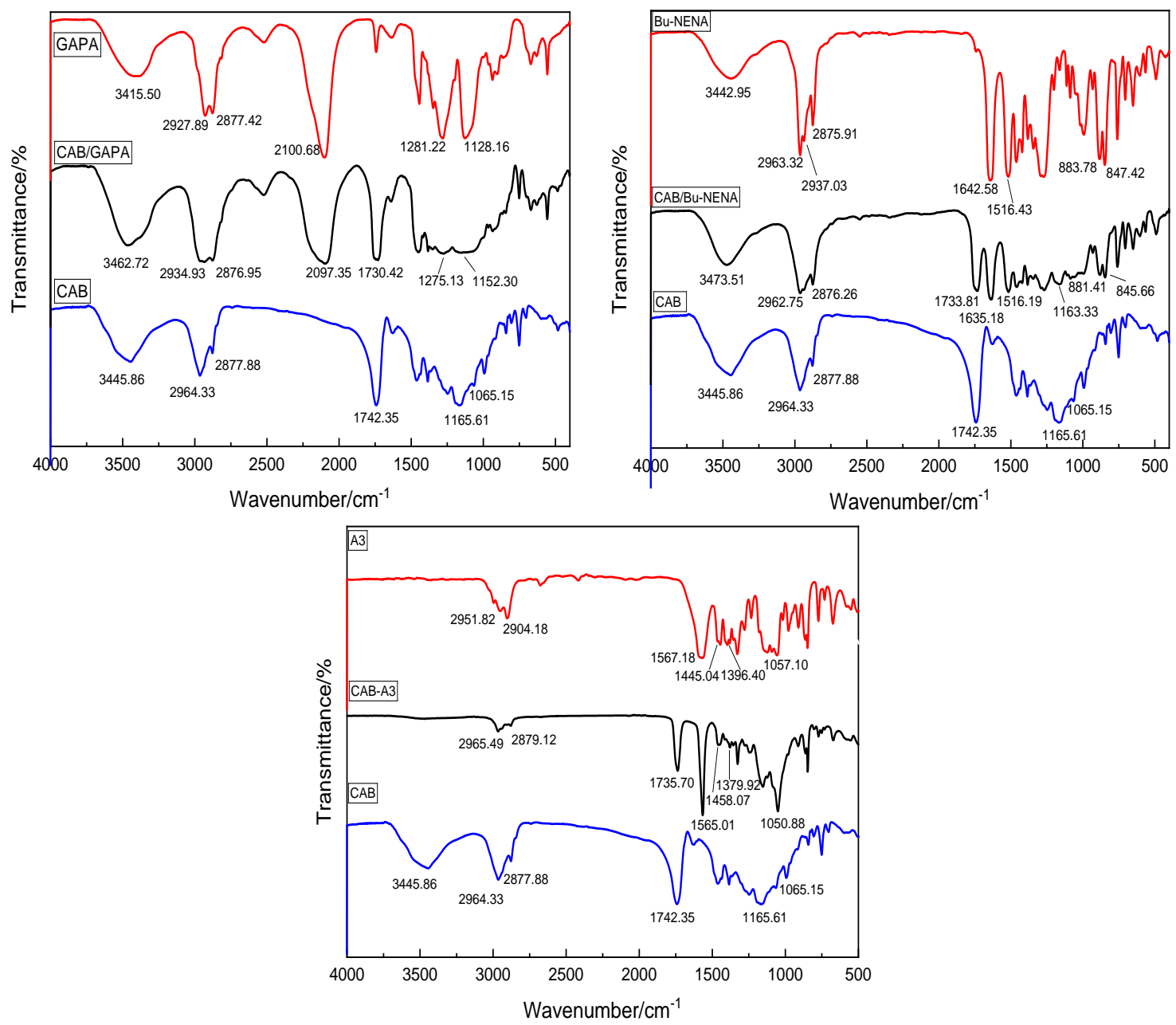

Figure 4. FT-IR spectra of $C A B$, plasticizer and $C A B /$ plasticizer systems.

\subsubsection{Compatibility}

The compatibilities between an explosive and its contacting materials can be evaluated by DCS and DTA. According to the National Military Standard of China GJB 772A-97 502.1, the compatibility can be classified into four levels: level A with $\Delta T_{p} \leq 2.0 /{ }^{\circ} \mathrm{C}$ and $\Delta E / E_{a} \leq 20 \%$, the system is compatible or highly compatible; level B with $\Delta T_{p} \leq 2.0 /{ }^{\circ} \mathrm{C}$ and $\Delta E / E_{a}>20 \%$, the system is slightly sensitized or fairly compatible; level $\mathrm{C}$ with $\Delta T_{p}>2.0 /{ }^{\circ} \mathrm{C}$ and $\Delta E / E_{a} \leq 20 \%$, the system is sensitized or poorly compatible; level D with $\Delta T_{p}>2.0 /{ }^{\circ} \mathrm{C}$ and $\Delta E / E_{a}>20 \%$, the system is hazardous. In the standard, $\Delta T_{p}$ is the change of the decomposition exothermal temperature, and $\Delta E / E_{a}$ is the changing rate of the apparent activation energy.

Figure 5 shows the DSC and DTA curves of $C A B$, the plasticizers and the $C A B /$ plasticizer systems at the heating rate of $10 \mathrm{~K} / \mathrm{min}$. Table 4 lists the compatibilities of $\mathrm{CAB}$ with three energetic plasticizers obtained by DSC and DTA. 

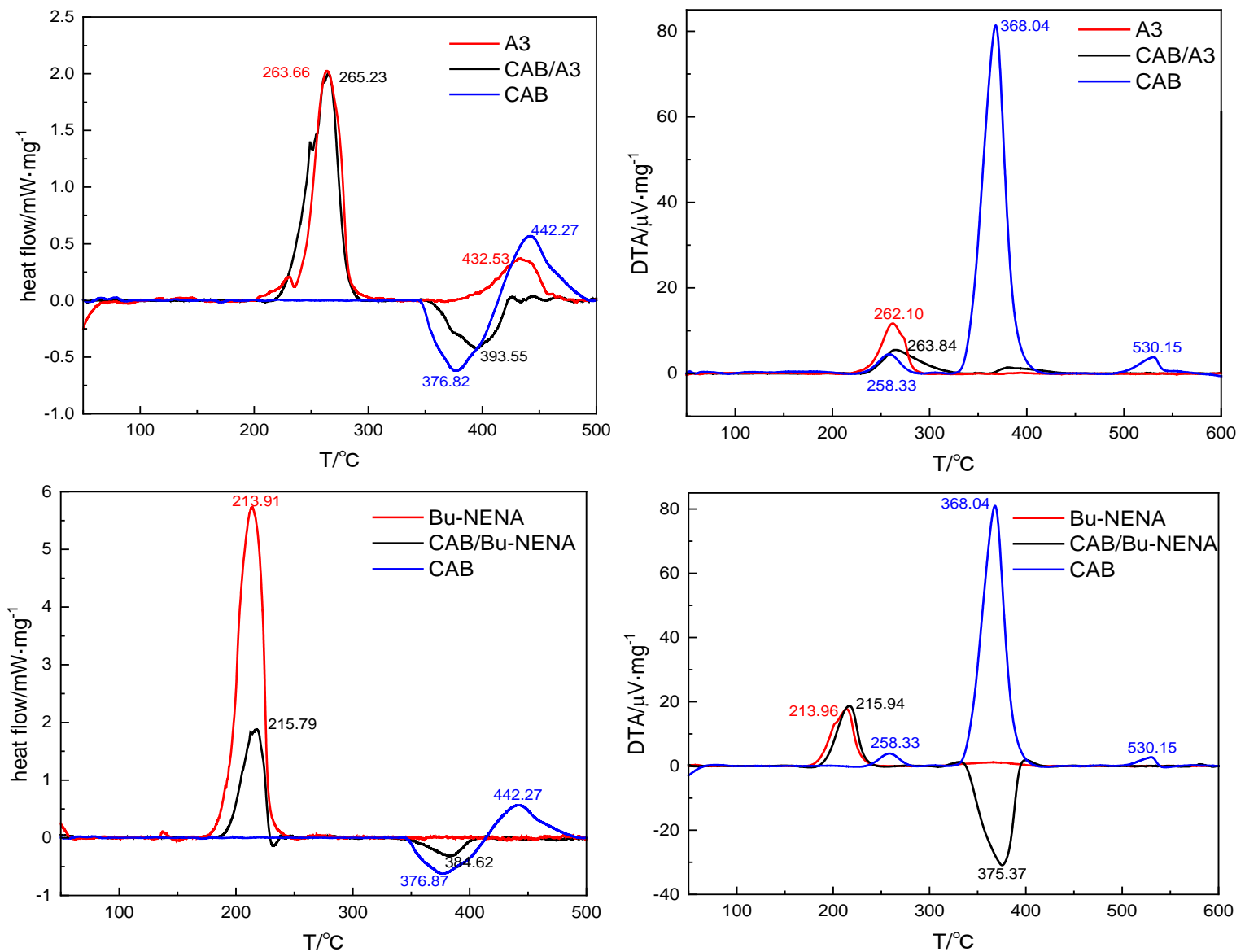

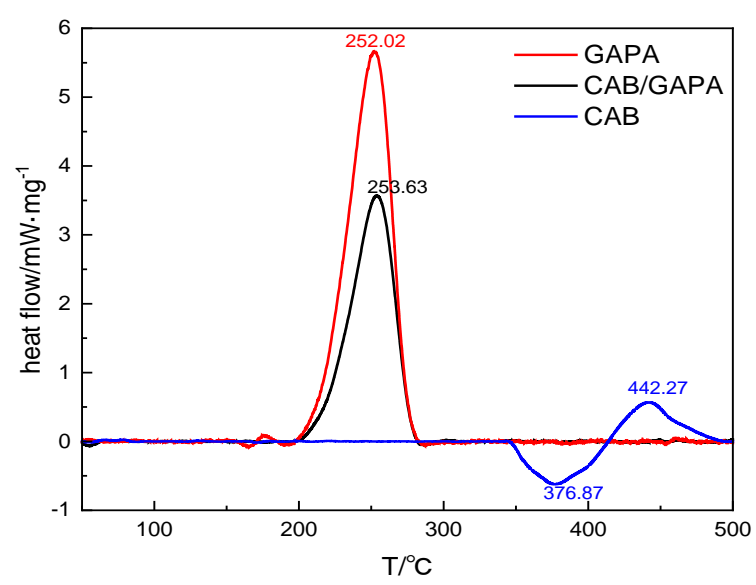

(a)

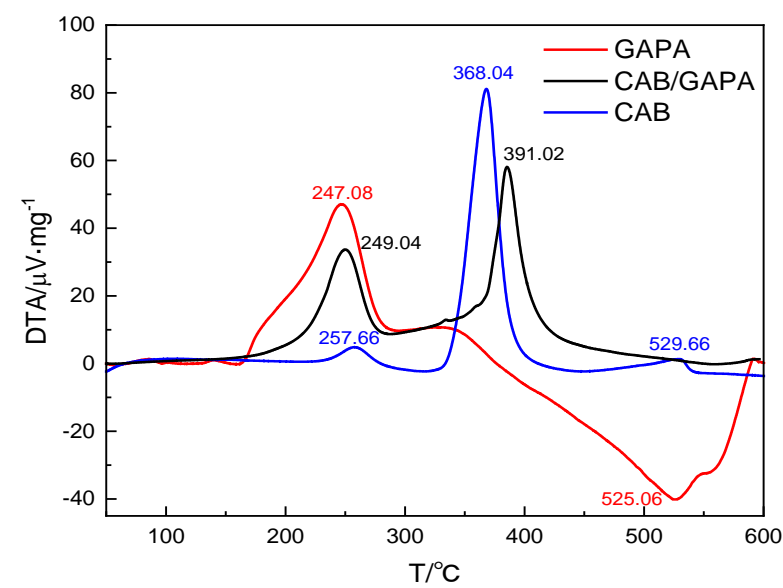

(b)

Figure 5. Differential scanning calorimetry (DSC) (a) and differential thermogravimetric analysis (DTA) (b) curves of $\mathrm{CAB}$, three plasticizers and the $\mathrm{CAB} /$ plasticizer systems at the heating rate of $10 \mathrm{~K} / \mathrm{min}$.

Table 4. $\Delta T_{p}$ and $\Delta E / E_{a}$ of different $C A B /$ plasticizer systems and the corresponding compatibility obtained from DSC/DTA.

\begin{tabular}{ccccccc}
\hline System & \multicolumn{2}{c}{$\Delta T_{p} /{ }^{\circ} \mathrm{C}$} & \multicolumn{2}{c}{$\left(\Delta E / E_{a}\right) / \%$} & \multicolumn{2}{c}{ Compatibility } \\
\hline & DSC & DTA & DSC & DTA & DSC & DTA \\
\hline CAB/A3 & 1.57 & 1.74 & 17.25 & 19.48 & Very good & Very good \\
CAB/Bu-NENA & 1.88 & 1.98 & 16.62 & 11.82 & Very good & Very good \\
CAB/GAPA & 1.61 & 1.96 & 18.05 & 18.80 & Very good & Very good \\
\hline
\end{tabular}


The first exothermic peak of $\mathrm{A} 3$ appears at $263.66^{\circ} \mathrm{C}$, which is caused by the main decomposition. The secondary decomposition of the partial decomposition products appeared at $432.53^{\circ} \mathrm{C}$. The main exothermic peak of $\mathrm{CAB} / \mathrm{A} 3$ is found at $265.23{ }^{\circ} \mathrm{C}$. The peak temperature shift $\Delta T_{p}$ is within $2{ }^{\circ} \mathrm{C}$ and the $\Delta E / E_{a}$ is calculated to be $17.25 \%$, indicating the compatibility of $\mathrm{CAB} / \mathrm{A} 3$ system reaches level A. The exothermic peak temperature of Bu-NENA is $213.91{ }^{\circ} \mathrm{C}$, and the main exothermic peak of $\mathrm{CAB} / \mathrm{Bu}-\mathrm{NENA}$ is at $215.79{ }^{\circ} \mathrm{C}$. The peak temperature shift $\Delta T_{p}$ is within $2{ }^{\circ} \mathrm{C}$ and the calculated $\Delta E / E_{a}$ is $16.62 \%$, suggesting the compatibility of CAB/Bu-NENA system is also level A. Similarly, the compatibility of $\mathrm{CAB} / \mathrm{GAPA}$ system is found to be level A with the exothermic peak temperatures of GAPA and CAB/Bu-NENA respectively at 252.02 and $253.63{ }^{\circ} \mathrm{C}$, and the $\Delta E / E_{a}$ of $18.05 \%$.

Similar results are also obtained by DTA (Table 4). The peak temperature shifts of all three $\mathrm{CAB} /$ plasticizer systems are within $2{ }^{\circ} \mathrm{C}$ and the corresponding $\Delta E / E_{a}$ values are less than $20.00 \%$. These results suggest that $\mathrm{A} 3, \mathrm{Bu}-\mathrm{NENA}$ and GAPA are compatible with $\mathrm{CAB}$ at level $\mathrm{A}$, and thus can be safely used in explosive design. In addition, the experimental compatibility results obtained by DSC/DTA are consistent with MD simulation results, indicating MD simulation is applicable to the characterization of the plasticized binders for the design of energetic materials.

\subsubsection{Mechanical Properties}

Figure 6 shows the tensile strengths $(\sigma)$, Young's moduli $(E)$ and strains at break $(\varepsilon)$ of the three $\mathrm{CAB} /$ plasticizer systems measured experimentally. The stress-strain curves of $\mathrm{CAB} /$ plasticizer systems were measured firstly and the values of $\sigma, E$ and $\varepsilon$ were calculated from the first linear part of the stress-strain curves (elastic domain), respectively.

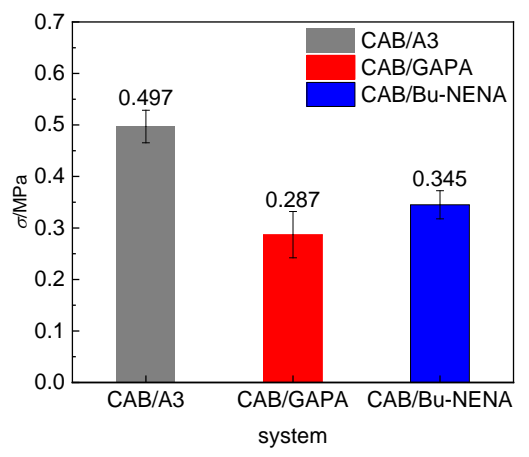

(a)

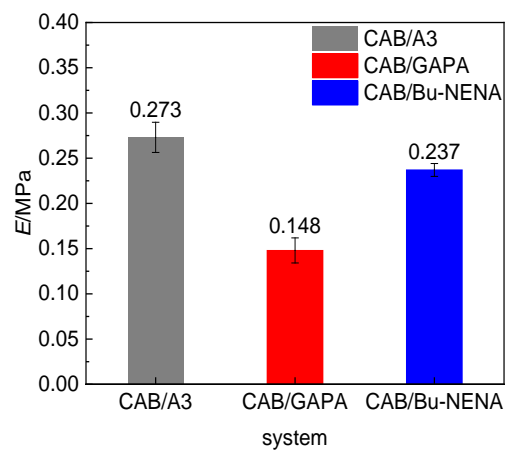

(b)

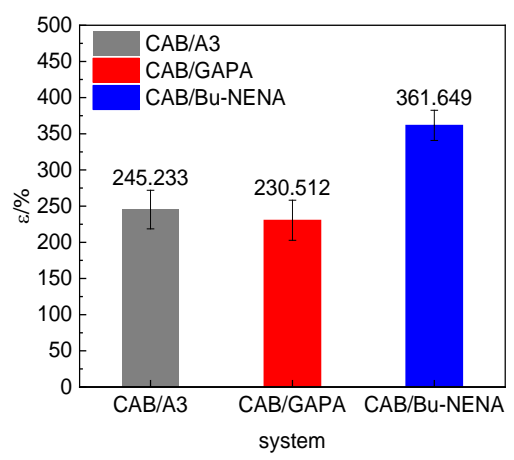

(c)

Figure 6. Mechanical properties of $\mathrm{CAB} /$ plasticizer systems measured experimentally: (a) Tensile strengths $(\sigma),(\mathbf{b})$ Young's moduli $(E)$, and (c) strains at break $\varepsilon$.

The tensile strengths $(\sigma)$ and Young's moduli $(E)$ of $\mathrm{CAB} /$ plasticizer systems are in the order of $\mathrm{CAB} / \mathrm{A} 3>\mathrm{CAB} / \mathrm{Bu}-\mathrm{NENA}>\mathrm{CAB} / \mathrm{GAPA}$, indicating that the mechanical strength and resistance capacity to deformation of $\mathrm{CAB} / \mathrm{A} 3$ are best, significantly better than $\mathrm{CAB} / \mathrm{Bu}-\mathrm{NENA}$ and $\mathrm{CAB} / \mathrm{GAPA}$. However, 
the strain at break $(\varepsilon)$ of $\mathrm{CAB} / \mathrm{Bu}-\mathrm{NENA}$ are higher than $\mathrm{CAB} / \mathrm{A} 3$ and $\mathrm{CAB} / \mathrm{GAPA}$, which means better deformability, but, worst stiffness. Tensile strength test results are consistent with MD simulation results, which further confirm the applicability of MD simulation to the design of energetic materials.

\section{Conclusions}

In the present work, the compatibilities between $\mathrm{CAB}$ and seven plasticizers were firstly evaluated numerously by MD simulation and compatible plasticizers are approximately selected. Afterwards, the mechanical properties of $\mathrm{CAB}$ with selected plasticizers were calculated by MD simulation. The mixed systems with suitable plasticizers were further characterized experimentally. Simulation results suggest that GAPA, Bu-NENA, A3 and DEGBAA are compatible with CAB well and other plasticizers including PETKAA, TMNTA and EGBAA are incompatible with CAB. The shear moduli $(G)$ of optimal $\mathrm{CAB} /$ plasticizer systems are similar, but their bulk moduli $(K)$, Poisson's ratios $(\mu), K / G$ ratios and Young's moduli $(E)$ are all in the order of $\mathrm{CAB} / \mathrm{Bu}-\mathrm{NENA}>\mathrm{CAB} / \mathrm{A} 3>\mathrm{CAB} / \mathrm{GAPA}$, suggesting the mechanical properties of $\mathrm{CAB} / \mathrm{Bu}-\mathrm{NENA}$ are the best.

FT-IR characterization suggests that no chemical reaction occurs during the mixing procedure of $\mathrm{CAB}$ and plasticizers, and these $\mathrm{CAB} /$ plasticizer systems are chemically stable. DSC/DTA analysis further demonstrates that A3, GAPA and Bu-NENA plasticizers are compatible with CAB at level $A$, and thus these energetic plasticizers are safe for the explosive designs with $C A B$ as binder. It is found by tensile strength measurements that tensile strengths $(\sigma)$ and Young's moduli $(E)$ of $\mathrm{CAB} /$ plasticizer systems are in the order of $\mathrm{CAB} / \mathrm{A} 3>\mathrm{CAB} / \mathrm{Bu}-\mathrm{NENA}>\mathrm{CAB} / \mathrm{GAPA}$, indicating that the mechanical strength and resistance capacity to deformation of $C A B / A 3$ are best, significantly better than $\mathrm{CAB} / \mathrm{Bu}-\mathrm{NENA}$ and $\mathrm{CAB} / \mathrm{GAPA}$. However, the strain at break $(\varepsilon)$ of $\mathrm{CAB} / \mathrm{Bu}-\mathrm{NENA}$ are higher than $\mathrm{CAB} / \mathrm{A} 3$ and $\mathrm{CAB} / \mathrm{GAPA}$, which means better deformability, but, worst stiffness.

All experimental results are consistent with MD simulation results well, indicating that MD simulation is a suitable study method for energetic material designs. Based on both simulation and experimental results, it can be concluded that A3, Bu-NENA and GAPA are the suitable plasticizers of $\mathrm{CAB}$ binder to improve the poor mechanical properties and processing properties of PBXs. Our work has provided a crucial guidance and reference for the formulation of PBXs using $C A B$ as the binder.

Author Contributions: The work presented here was carried out in collaboration with all authors. W.W., L.L. and Y.C. designed the works and wrote the paper; W.W., S.J. and Y.W. performed the molecular dynamics simulation and data analysis; W.W. and G.L. compared the simulation results with the experimental results. All authors have read and agreed to the published version of the manuscript.

Funding: This work was supported by "the Fundamental Research Funds for the Central Universities".

Acknowledgments: This work was supported by "the Fundamental Research Funds for the Central Universities".

Conflicts of Interest: The authors declare no conflict of interest. The sponsors had no role in the design, execution, interpretation, or writing of the study.

\section{References}

1. Podshivalov, A.; Besson, F.; Budtova, T.; Bronnikov, S. Morphology and improved impact strength of cellulose acetate butyrate blended with polyethylene copolymer. eXPRESS Polym. Lett. 2018, 12, 856-866. [CrossRef]

2. Li, X.; Chen, S.; Wang, X.; Shang, F.; Dong, W.; Yu, Z.; Yu, Y.; Zou, H.; Jin, S.; Chen, Y. Effect of polymer binders on safety and detonation properties of $\mathcal{E}$-CL-20-based pressed-polymer-bonded explosives. Mater. Express 2017, 7, 209-215. [CrossRef]

3. Lan, G.; Jin, S.; Jing, B.; Chen, Y.; Wang, D.; Li, J.; Wang, N.; Chen, M. Investigation into the Temperature Adaptability of HNIW-based PBXs. Propellants Explos. Pyrotech. 2019, 44, 327-336. [CrossRef]

4. Dandekar, A.; Roberts, Z.A.; Paulson, S.; Chen, W.; Son, S.F.; Koslowski, M. The effect of the particle surface and binder properties on the response of polymer bonded explosives at low impact velocities. Comput. Mater. Sci. 2019, 166, 170-178. [CrossRef]

5. Badgujar, D.; Talawar, M.; Zarko, V.; Mahulikar, P. New directions in the area of modern energetic polymers: An overview. Cpmbust. Explo. Shock+ 2017, 53, 371-387. [CrossRef] 
6. Singh, A.; Radhakrishnan, S.; Vijayalakshmi, R.; Talawar, M.; Kumar, A.; Kumar, D. Screening of polymer-plasticizer systems for propellant binder applications: An experimental and simulation approach. J. Energy Mater. 2019, 37, 365-377. [CrossRef]

7. Bergh, M.; Caleman, C. A validation study of the general amber force field applied to energetic molecular crystals. J. Energy Mater. 2016, 34, 62-75. [CrossRef]

8. Jangid, S.K.; Radhakrishnan, S.; Solanki, V.J.; Singh, M.K.; Pandit, G.; Vijayalakshmi, R.; Sinha, R.K. Evaluation studies on partial replacement of RDX by spherical NTO in HTPB-based insensitive sheet explosive formulation. J. Energy Mater. 2019, 37, 320-330. [CrossRef]

9. Cruz, J.N.; Moraes, E.S.; Pantoja, R.P.; Pereira, T.S.; Mota, G.V.; Neto, A.M.J.C. Sensors Using the Molecular Dynamics of Explosives in Carbon Nanotubes Under External Uniform Electric Fields. J. Nanosci. Nanotechnol. 2019, 19, 5687-5691. [CrossRef]

10. Yılmaz, G.A.; Şen, D.; Kaya, Z.T.; Tinçer, T. Effect of inert plasticizers on mechanical, thermal, and sensitivity properties of polyurethane-based plastic bonded explosives. J. Appl. Polym. Sci. 2014, 131. [CrossRef]

11. Sun, H. COMPASS: An ab initio force-field optimized for condensed-phase applications overview with details on alkane and benzene compounds. J. Phys. Chem. B 1998, 102, 7338-7364. [CrossRef]

12. El-Sakhawy, M.; Kamel, S.; Salama, A.; Sarhan, H.A. Carboxymethyl cellulose acetate butyrate: A review of the preparations, properties, and applications. J. Drug Deliv. 2014, 2014, 575969. [CrossRef]

13. Wingborg, N.; Eldsater, C. 2,2-Dinitro-1,3-Bis-Nitrooxy-Propane (NPN): A New Energetic Plasticizer. Propellants Explos. Pyrotech. 2002, 27, 314-319. [CrossRef]

14. Drees, D.; Loffel, D.; Messmer, A.; Schmid, K. Synthesis and Characterization of Azido Plasticizer. Propellants Explos. Pyrotech. 1999, 24, 159-162. [CrossRef]

15. Kumari, D.; Singh, H.; Patil, M.; Thiel, W.; Pant, C.S.; Banerjee, S. Synthesis, characterization, thermal and computational studies of novel tetra-azido esters as energetic plasticizers. Thermochim. Acta 2013, 562, 96-104. [CrossRef]

16. Zhao, B.; Gao, F.; Wang, Y.; Liu, Y.; Chen, B.; Pan, Y. Azido Energetic Plasticizers for Gun and Rocket Propellants. Prog. Chem. 2019, 31, 475-490. [CrossRef]

17. Nair, U.R.; Asthana, S.N.; Rao, A.S.; Gandhe, B.R. Advances in High Energy Materials. Def. Sci. J. 2010, 60, 137-151. [CrossRef]

18. Amim, J., Jr.; Blachechen, L.S.; Petri, D.F.S. Effect of sorbitan-based surfactants on glass transition temperature of cellulose esters. J. Therm. Anal. Calorim. 2012, 107, 1259-1265. [CrossRef]

19. Khanniche, S.; Mathieu, D.; Barthet, C.; Pereira, F.; Hairault, L. Molecular dynamics simulation of gaseous nitroaromatic compounds interacting with silica surfaces under various humidity conditions. Appl. Surf. Sci. 2018, 455, 533-542. [CrossRef]

20. Mendonça, F.B.; Gonçalves, R.F.; Urgessa, G.S.; Iha, K.; Domingues, M.; Rocco, J.A. Computational Chemistry Employment in Verification and Validation of Detonation Pressure of Plastic Explosive-Pbx. Quim. Nova 2018, 41, 310-314. [CrossRef]

21. Sadeghi, A.; Nazem, H.; Rezakazemi, M.; Shirazian, S. Predictive construction of phase diagram of ternary solutions containing polymer/solvent/nonsolvent using modified Flory-Huggins model. J. Mol. Liq. 2018, 263, 282-287. [CrossRef]

22. Kundu, B.K.; Mobin, S.M.; Mukhopadhyay, S. Mechanistic and thermodynamic aspects of a pyrene-based fluorescent probe to detect picric acid. New J. Chem. 2019, 43, 11483-11492. [CrossRef]

23. Dahiwale, S.; Bhongale, C.; Roy, S.; Navle, P.; Asthana, S. Studies on ballistic parameters of di-butyl phthalate-coated triple base propellant used in large caliber artillery gun ammunition. J. Energy Mater. 2019, 37, 98-109. [CrossRef]

24. Singh, A.; Kumar, R.; Soni, P.K.; Singh, V. Compatibility and thermokinetics studies of octahydro-1, 3, 5, 7-tetranitro-1, 3, 5, 7-tetrazocine with polyether-based polyurethane containing different curatives. J. Energy Mater. 2019, 37, 141-153. [CrossRef]

25. Ramanaiah, S.; Rani, P.R.; Sreekanth, T.; Reddy, K.S. Determination of Hansen solubility parameters for the solid surface of cellulose acetate butyrate by inverse gas chromatography. J. Macromol. Sci. Part B Phys. 2011, 50, 551-562. [CrossRef]

26. Lindblad, M.S.; Keyes, B.M.; Gedvilas, L.M.; Rials, T.G.; Kelley, S.S. FTIR imaging coupled with multivariate analysis for study of initial diffusion of different solvents in cellulose acetate butyrate films. Cellulose 2008, 15, 23-33. [CrossRef] 
27. Cappello, M.; Lamia, P.; Mura, C.; Polacco, G.; Filippi, S. Azidated Ether-Butadiene-Ether Block Copolymers as Binders for Solid Propellants. J. Energy Mater. 2016, 34, 318-341. [CrossRef]

28. Bafghi, S.M.A.T.; Kamalvand, M.; Morsali, A.; Bozorgmehr, M.R. Radial distribution function within the framework of the Tsallis statistical mechanics. Physical A 2018, 506, 857-867. [CrossRef]

29. Larsen, M.L.; Shaw, R. A method for computing the three-dimensional radial distribution function of cloud particles from holographic images. Atmos. Meas. Tech. 2018, 11, 4261. [CrossRef]

30. García-Negrón, V.; Oyedele, A.D.; Ponce, E.; Rios, O.; Harper, D.P.; Keffer, D.J. Evaluation of nano-and mesoscale structural features in composite materials through hierarchical decomposition of the radial distribution function. J. Appl. Crystallogr. 2018, 51, 76-86. [CrossRef]

31. Liu, N.; Li, Y.N.; Zeman, S.; Shu, Y.J.; Wang, B.Z.; Zhou, Y.S.; Zhao, Q.L.; Wang, W.L. Crystal morphology of 3, 4-bis (3-nitrofurazan-4-yl) furoxan (DNTF) in a solvent system: Molecular dynamics simulation and sensitivity study. CrystEngComm 2016, 18, 2843-2851. [CrossRef]

32. Chen, F.; Zhou, T.; Li, J.; Wang, X.L.; Cao, D.L.; Wang, J.L.; Yang, Z.J. Crystal morphology of dihydroxylammonium 5, 5'-bistetrazole-1, 1'-diolate (TKX-50) under solvents system with different polarity using molecular dynamics. Comput. Mater. Sci. 2019, 168, 48-57. [CrossRef]

33. Shu, Y.; Zhang, S.W.; Shu, Y.J.; Liu, N.; Yi, Y.; Huo, J.C.; Ding, X.Y. Interactions and physical properties of energetic poly-(phthalazinone ether sulfone ketones)(PPESKs) and $\varepsilon$-hexanitrohexaazaisowurtzitane ( $\varepsilon$-CL-20) based polymer bonded explosives: A molecular dynamics simulations. Struct. Chem. 2019, 30, 1041-1055. [CrossRef]

34. Li, J.; Jin, S.S.; Lan, G.C.; Ma, X.; Ruan, J.; Zhang, B.; Chen, S.S.; Li, L.J. Morphology control of 3-nitro-1, 2, 4-triazole-5-one (NTO) by molecular dynamics simulation. CrystEngComm 2018, 20, 6252-6260. [CrossRef]

35. Sekkar, V.; Alex, A.S.; Kumar, V.; Bandyopadhyay, G.G. Theoretical evaluation of crosslink density of chain extended polyurethane networks based on hydroxyl terminated polybutadiene and butanediol and comparison with experimental data. J. Energy Mater. 2018, 36, 38-47. [CrossRef]

36. Lin, H.; Chen, J.F.; Cui, Y.M.; Zhang, Z.J.; Yang, D.D.; Zhu, S.G.; Li, H.Z. A DFT-D study on structural, electronic, thermodynamic, and mechanical properties of HMX/MPNO cocrystal under high pressure. J. Energy Mater. 2017, 35, 157-171. [CrossRef]

37. Ahmadi, S.H.; Keshavarz, M.H.; Hafizi Atabak, H.R. Introducing Laser Induced Breakdown Spectroscopy (LIBS) as a Novel, Cheap and Non-destructive Method to Study the Changes of Mechanical Properties of Plastic Bonded Explosives (PBX). Z. Anorg. Allg. Chem. 2018, 644, 1667-1673. [CrossRef]

38. Lan, G.C.; Jin, S.S.; Li, J.; Wang, J.Y.; Lu, Z.Y.; Wu, N.N.; Li, L.J.; Wang, D.X. Miscibility, glass transition temperature and mechanical properties of NC/DBP binary systems by molecular dynamics. Propellants Explos. Pyrotech. 2018, 43, 559-567. [CrossRef]

39. Li, J.; Jin, S.S.; Lan, G.C.; Chen, S.S.; Li, L.J. Modelling. Molecular dynamics simulations on miscibility, glass transition temperature and mechanical properties of PMMA/DBP binary system. J. Mol. Graph. Model. 2018, 84, 182-188. [CrossRef]

40. Shu, Y.; Yi, Y.; Huo, J.C.; Liu, N.; Wang, K.; Lu, Y.Y.; Wang, X.C.; Wu, Z.K.; Shu, Y.J.; Zhang, S.W. Interactions between poly-(phthalazinone ether sulfone ketone)(PPESK) and TNT or TATB in polymer bonded explosives: A molecular dynamic simulation study. J. Mol. Model. 2017, 23, 334. [CrossRef]

41. Lu, Y.Y.; Shu, Y.J.; Liu, N.; Shu, Y.; Wang, K.; Wu, Z.K.; Wang, X.C.; Ding, X.Y. Theoretical simulations on the glass transition temperatures and mechanical properties of modified glycidyl azide polymer. Comput. Mater. Sci. 2017, 139, 132-139. [CrossRef]

42. Hang, G.Y.; Yu, W.L.; Wang, T.; Wang, J.T.; Li, Z. Theoretical investigations on stabilities, sensitivity, energetic performance and mechanical properties of CL-20/NTO cocrystal explosives by molecular dynamics simulation. Theor. Chem. Acc. 2018, 137, 114. [CrossRef]

43. Gumieniczek, A.; Galeza, J.; Berecka, A.; Mroczek, T.; Wojtanowski, K.; Lipska, K.; Skarbek, J. Chemical stability and interactions in a new antihypertensive mixture containing indapamide and dihydralazine using FT-IR, HPLC and LC-MS methods. RSC Adv. 2018, 8, 36076-36089. [CrossRef]

(C) 2020 by the authors. Licensee MDPI, Basel, Switzerland. This article is an open access article distributed under the terms and conditions of the Creative Commons Attribution (CC BY) license (http://creativecommons.org/licenses/by/4.0/). 